\title{
In-mouth mechanism leading to the perception of fat in humans: from detection to preferences. The particular role of saliva
}

\author{
Gilles FERON \\ Julie POETTE \\ INRA, \\ UMR1324 Centre des Sciences du Goût \\ et de I'Alimentation, \\ F-21000 Dijon, France ; \\ CNRS, \\ UMR6265 Centre des Sciences du Goût \\ et de I'Alimentation, \\ F-21000 Dijon, \\ France ; \\ Université de Bourgogne, \\ UMR Centre des Sciences du Goût et de \\ I'Alimentation, \\ F-21000 Dijon, \\ France \\ $<$ Gilles.Feron@dijon.inra.fr>
}

Article received 30 November 2012

Accepted 6 December 2012

In humans, orality combines all the functions of the orofacial sphere (in which the mouth is the key organ), i.e., ventilation, expression, food breakdown, and sensory perception. The mouth is the first organ to perceive food and the different signalling events associated with food breakdown. The release of sensory stimuli, major contributors to our preferences and rejections, also occurs within the mouth. These events are extremely complex, and as such, their description necessitates combining many variables from different disciplines, i.e., physics, chemistry, physiology, psychology, behavioural science, and food science.

\begin{abstract}
Mécanismes en bouche conduisant à la perception du gras chez I'Homme : de la détection aux préférences. Le rôle particulier de la salive In humans, the perception of fat in food is a complex process involving many sensory modalities (texture, aroma and flavour). The mouth is the first place in which the process of digestion begins. During this process, a bolus is formed in which saliva is significantly incorporated. For solids and semi-solid fatty matrices, saliva and the shear forces applied during mastication contribute to their breakdown and/or destabilisation in emulsified systems. These mechanisms are often dependent on the fat content of the food and thus play an important role in not only the perception of texture but also the release of compounds responsible for the flavour of "fat". In addition, saliva is directly involved in the orosensory detection of triglycerides and their hydrolysis products, i.e., free fatty acids, which occurs at different detection levels, i.e., taste and multimodal. Concerning taste detection, it has been shown that the level of salivary lipolysis is related to the sensitivity of the subject to triolein and oleic acid. Regarding multimodal detection, the antioxidant power and protein composition variables are related to sensory characteristics, such as textural and olfactory perception, of the emulsion. Interestingly, the involvement of some of these salivary variables in the perceived intensity and preference towards model oil emulsions was also shown. In addition to detection, these mouth processes also contribute greatly to a preference for or rejection of fat. Preferences are related to not only the perception of texture but also gustatory and olfactory components of fat.
\end{abstract}

Key word: human, saliva, fat perception, lipolysis, emulsion, mouth

In this context, the associated sensory mechanisms involved in fat perception are an example of this complexity because fat perception is a multisensory integration of olfactory, gustatory and somatosensory cues, in which foodrelated oral processes play an essential role. The related in-mouth mechanisms often result in melting the product, adhering to mucous membranes and mixing with saliva.

The rate of incorporated saliva can depend on not only the nature of the product consumed but also the subject consuming the product (Gaviao and van der Bilt, 2004). For instance, a recent study conducted on 6 cheese-like products showed an average incorporation of saliva into the matrix of $20 \%$ to $50 \%$, depending on the firmness of the product and the level of fat (Guichard et al., 2010). However, this study also revealed large interindividual variability. For one product, the level of saliva incorporated varied from $20 \%$ to $80 \%$ by subject. Thus, the swallowed product is very different from that put in the mouth, and interactions between the fatty matrix and saliva can cause a significant change in not only the release and perception of aromas and fat taste but also texture. Indeed, human saliva is composed of a large

To cite this article: Feron G, Poette J. In-mouth mechanism leading to the perception of fat in humans: from detection to preferences. The particular role of saliva. OCL 2013; 20(2): 102-107. doi : 10.1684/ocl.2012.0496 
number of molecules of varying sizes that can interact more or less strongly with fat (Salles et al., 2011). Moreover, studies suggest the role of different physicochemical and biochemical salivary characteristics in the orosensory perception of fat. Thus, the presence of enzymes (e.g., lipase, lysozyme, and amylase) and proteins (e.g., lipocalin, mucin, and protein rich in proline), $\mathrm{pH}$ and the antior pro-oxidant buffering capacity of saliva may be involved in the release and oxidation of compounds, aromas and lipids or modification of the texture in the mouth. Some compounds from these reactions can then be perceived by the consumer and have a positive or negative impact (Chale-Rush et al., 2007a). These possible effects are summarised in table 1 .

Based on the most recent results obtained in the field, this short review will detail the role of different salivary characteristics on fat detection initially and fat perception and preference subsequently.

\section{Possible role of saliva in the detection of fat}

The oral detection of fat in humans was shown for the first time in 1996 in the studies published by Richard Mattes, which showed that oronasal exposure to dietary fat can influence postprandial metabolism (Mattes, 1996). The conclusions from this work were subsequently confirmed in many papers published by the same research group (Chale-Rush et al., 2007a; Chale-Rush et al., 2007b; Mattes, 2005; Mattes, 2002). In addition to studies by Mattes, there are a large number of papers describing the mechanisms of fat oral detection in rats and mice (DegracePassilly and Besnard, 2012; Laugerette et al., 2007; Laugerette et al., 2005). In particular, the involvement of the fatty acid transporter CD36, the delayedrectifying potassium (DRK) channel Kv1.5 and the G protein-coupled receptor-120 (GPCR120) was demonstrated in the detection of fat at the oral level (see (Khan and Besnard, 2009) for review). In humans, the role of CD36 in the perception of fat was suspected, and recently published results showed a direct relation between the level of CD36 expression in obese subjects and the sensory detection threshold for oleic acid and triolein (Pepino et al., 2012). In addition to related receptor mechanisms, perireceptor events have been little investigated or described in the literature. However, they can contribute to either taste or the multimodal detection of fat. Among them, one of the main salivary factors that could contribute to the taste perception of fat is saliva lipase. The role of saliva lipase in the oral detection of fat has been clearly demonstrated in rats. In humans, it has been the subject of controversy for 20 years, although its contribution was suspected by some research groups (Kawai and Fushiki, 2003). Recently, saliva lipase has gained interest, with studies conducted on a significant number of subjects to determine its potential role as a biomarker for oral phthalate activation (Voho et al., 2006) and oral fatty acid sensitivity (Stewart et al., 2010). In 2012, indirect evidence of a positive saliva lipase contribution to the oral detection of triolein was observed in obese subjects (Pepino et al., 2012). This potential role of lipase in fat sensitivity was reinforced with recent results obtained by our research group. A study was conducted on 15 subjects from a panel of 50 to compare salivary composition and flow. In particular, lipolysis, total antioxidant status, amylolysis, protein, LCN1, lysozyme amounts and salivary flow were determined with regard to oleic acid taste sensitivity.

Table 1. Potential impact of salivary components and parameters on the different modalities involved in fat sensory perception (adapted from Salles et al., 2011).

\begin{tabular}{|llll|}
\hline $\begin{array}{l}\text { Salivary component } \\
\text { \& parameter }\end{array}$ & Potential targets & Products/effects & $\begin{array}{l}\text { Potential impact on } \\
\text { fat perception }\end{array}$ \\
\hline $\mathrm{pH}$ & Free fatty acids, volatile acids & Salt formation, precipitation & Aroma and taste \\
\hline $\begin{array}{l}\text { Dry matter (salts, small } \\
\text { molecules, etc.) }\end{array}$ & Fat-related aroma compounds & Aroma release & Aroma perception \\
\hline $\begin{array}{l}\text { Total antioxidant } \\
\text { status (TAS) }\end{array}$ & Polyunsaturated fatty acids & $\begin{array}{l}\text { Aldehyde, alcohol, } \\
\text { and ketone synthesis }\end{array}$ & $\begin{array}{l}\text { Aroma } \\
\text { After taste }\end{array}$ \\
\hline $\begin{array}{l}\alpha-\text { Amylase } \\
\text { Lipolysis }\end{array}$ & $\begin{array}{l}\text { Starch } \\
\text { Aroma compounds }\end{array}$ & $\begin{array}{l}\text { Texture } \\
\text { Aroma release }\end{array}$ & Aroma \\
\hline Proteolysis & Tri-, di-, and mono-glycerides & Free fatty acids & Aroma and taste \\
\hline Proteins & Protein stabilisers, fat droplets & Emulsion destabilisation & Texture \\
\hline $\begin{array}{l}\text { Mucins (Muc5B } \\
\text { \& Muc 7B) }\end{array}$ & Aroma compounds & Aroma release & Aroma \\
\hline $\begin{array}{l}\text { Protein rich in } \\
\text { proline (PRP)? }\end{array}$ & Fat droplet (depletion) & Emulsion (de)stabilisation & Texture \\
\hline $\begin{array}{l}\text { Lysozyme } \\
\text { Lipocalins }\end{array}$ & Fat droplet & Emulsion (de)stabilisation? & Texture? \\
\hline
\end{tabular}




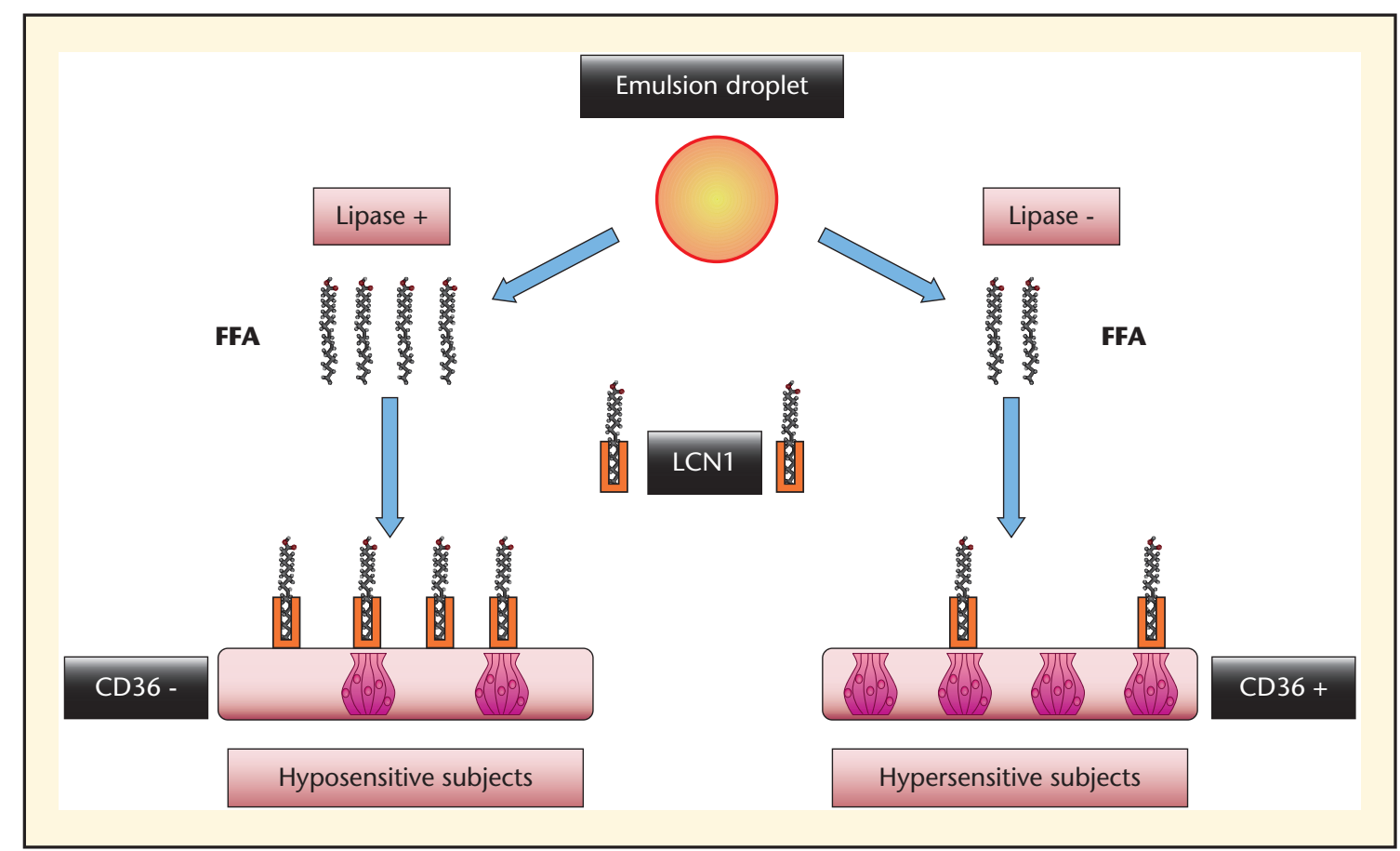

Figure 1. Schematic representation of the causal hypothesis formulated from the different correlations observed between fat taste sensitivity and saliva composition (Pepino et al., 2012; Poette et al., 2012). In this hypothesis, the level of free fatty acids detected is regulated by lipolysis activity against the emulsion droplet. In hyposensitive subjects, a high level of lipolysis is necessary to release a sufficient amount of free fatty acids from the emulsion to be detected. The solubilisation of the fatty acids is regulated by LCN1, which is not a limited component in this case. Considering the conclusion from Pepino's work (Pepino et al., 2012), hyposensitive subjects also express low levels of CD36 receptors. In hypersensitive subjects, the threshold amount of free fatty acids necessary to be detected is considerably lower, explaining the low level of lipase observed in these subjects. Moreover, higher CD36 expression permits a better detection of the FFAs released from the lipolysis activity. FFA = free fatty acid, LCN1 = lipocalin 1.

The results permitted us to identify hyper- and hyposensitive subjects to oleic acid. Interestingly, a strong correlation was observed between the level of saliva lipolysis and subject taste sensitivity to oleic acid (Poette et al., 2012), with hyposensitive subjects showing a high level of lipolysis and hypersensitive subjects showing a low level. Surprisingly, LCN1 was not identified as a regulatory variable in the detection of oleic acid. Based on this result and Pepino's work, a causal hypothesis can be proposed for the taste detection of fat (figure 1).

Saliva can also contribute to the multimodal detection of fat. In the same study conducted by Poette et al., the multimodal detection threshold for oleic acid was measured in addition to the taste threshold. With regard to the taste threshold, hypo- and hypersensitive subjects were identified, and some salivary components were observed to contribute to the multimodal threshold. Interestingly, these components were different from those observed for the taste threshold (in order of importance): protein amount $>$ lysozyme level $>$ saliva flow $>$ TAS. Regarding the taste threshold, a causal hypothesis can be proposed to explain the relation between these salivary markers and multimodal sensitivity for oleic acid (figure 2).

\section{Possible role of saliva in the perception of and preference for fat}

The contribution of saliva to fat perception and preferences has been principally investigated in studies on fat emulsion in relation to textural changes. In particular, the role of specific salivary proteins in the structural change of fat emulsions in the mouth has been demonstrated. Salivary amylase and mucin, in conjunction with the shear forces due to tongue movement, play an important role in the phenomena of flocculation and coalescence that occur during the consumption of oil-in-water emulsions. These changes in the structure of the emulsion have an impact on the perception of the products. In particular, high flocculation and coalescence lead to large droplet formation and more coating of the surface of the tongue. The consequences in terms of sensory perception are a higher impression of coating, creaminess, melting, fat texture and sliminess, which are considered to be preferred by the consumer. In contrast, little or no changes in the size of emulsion particles in the mouth increase the friction of the product on the tongue and the impression of astringency, roughness and dryness, which contribute more to the rejection of the product (Benjamins et al., 2009; Dresselhuis et al., 2008a; Dresselhuis et al., 2008b; Silletti et al., 2007; van Aken et al., 2007; Vingerhoeds et al., 2005; Vingerhoeds et al., 2008).

In addition, interactions can occur between saliva and the volatiles responsible for the fat note (Feron and Guichard, 2010). This is particularly 


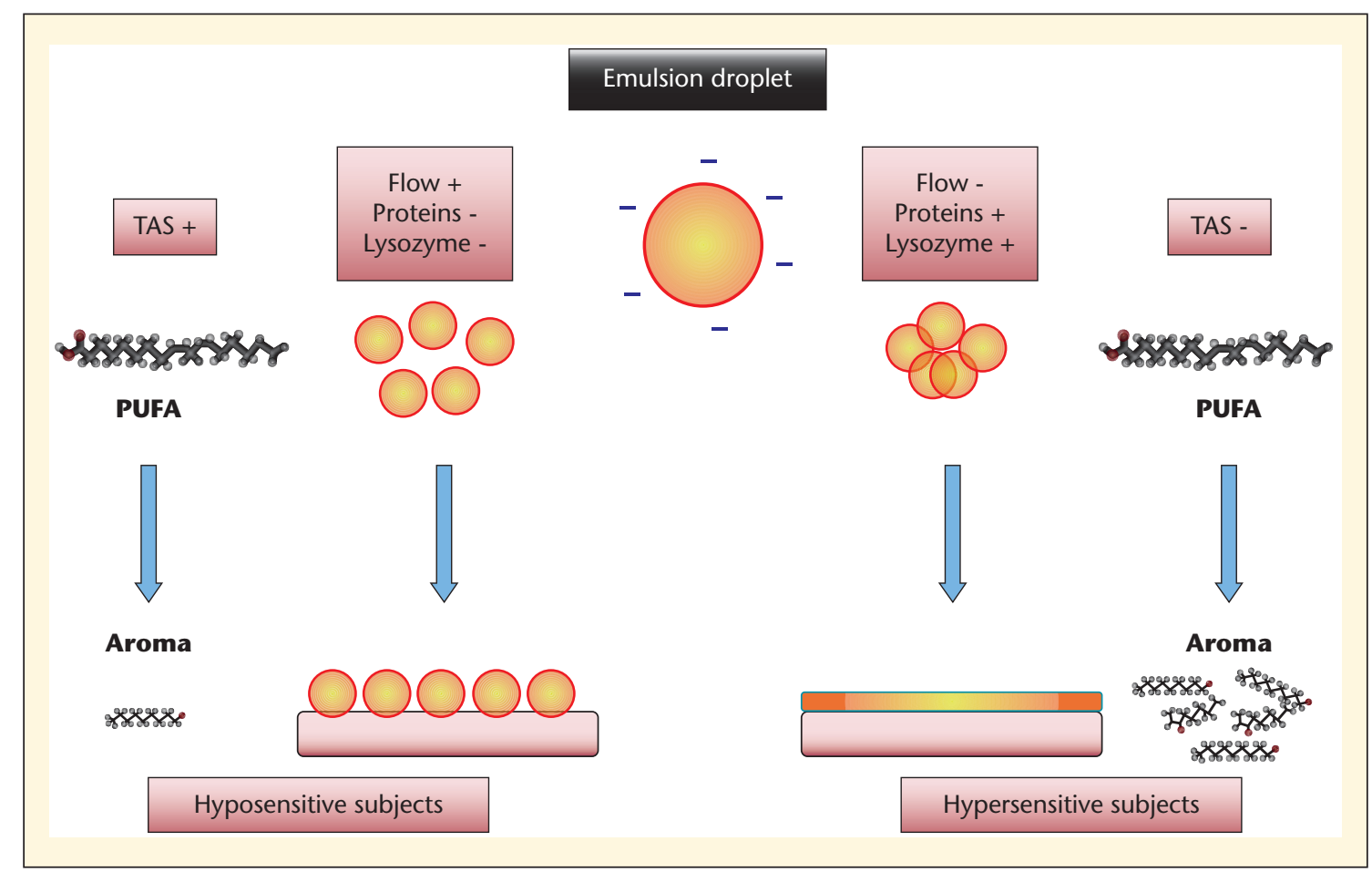

Figure 2. Schematic representation of the causal hypothesis formulated from the different correlations observed between fat multimodal sensitivity and saliva composition (Poette et al., 2012). In this hypothesis, saliva can act on two characteristics, i.e., texture and olfaction. In hypersensitive subjects, low salivary flow and a high amount of proteins and lysozyme can contribute to a higher retention and destabilisation of the emulsion at the surface of the tongue, enhancing the perception of fat texture. Additionally, low TAS can be interpreted as a higher sensitivity of these subjects to volatile compounds resulting from the oxidation of unsaturated fatty acids. Oxidation can occur either in the emulsion or in the oral cavity during fat consumption. Conversely, in hyposensitive subjects, a high flow and low level of protein and lysozyme can contribute to a fast oral clearance of the emulsion just after consumption. Moreover, high TAS may lead to a low sensitivity of these subjects to volatile compounds resulting from the oxidation of unsaturated fatty acids. PUFA = polyunsaturated fatty acid, TAS = total antioxidant status.

relevant for volatile acids that significantly contribute to the taste of fat. At the $\mathrm{pH}$ of saliva, most of these acids would be in a dissociated form and thus become non-volatile extremely fast (Poette et al., 2010). This phenomenon leads to the question of the taste perception of these compounds rather than olfactory perception. Saliva can also promote the release of aromas by a salting out effect, as previously shown in other food matrices (Genovese et al., 2009). As products that are high in fat, this effect was suspected in cheese-type matrices, in which the rate of saliva incorporation is slightly dependent on the fat content (Guichard et al., 2010). In addition, recent results obtained in vitro of spreadable fats and the volatile compounds used for their flavouring showed that the combined effects of interaction and salting out depended mainly on the chemical nature of the studied molecule (Poette et al., 2010).
Some recent works attempted to link saliva composition to perceived intensity and preferences for oil emulsion (Neyraud et al., 2012) in humans. Interestingly, salivary flow and lipolysis were found to be the variables that contributed the most to explaining preferences: subjects with high lipolysis and low flow showed poor preferences for the emulsion and vice versa.

The oral perception of and preference for fat has also been investigated at a central level. The research group of Edmund Rolls related the level of fat (un) pleasantness to the activation of brain areas. We will not go into deeper detail on Rolls and collaborator's results, but some main conclusions of these works are particularly interesting in the context of this paper. First, it has been shown by MRI that the brain areas activated by the oral perception of fattiness were different from those of (un)pleasantness. Second, the neurons that respond to fat in the mouth respond on the basis of its oily texture. Third, the neurons that respond to free fatty acid do not respond to fat in the mouth, although other neurons do and may contribute to the unpleasantness of rancid fat (Grabenhorst et al., 2011; Rolls, 2011; Rolls, 2010). These results raised the question of the positive and negative hedonic value of free fatty acids in the fat product or generated when it is put in the mouth.

Based on these different studies, a scheme of the involvement of saliva in the perception of and preference for fat is proposed in figure 3 .

\section{Conclusion}

In this short review, we have tried to provide an overview of the possible role of saliva in the detection, perception and preference for fat in humans, with 


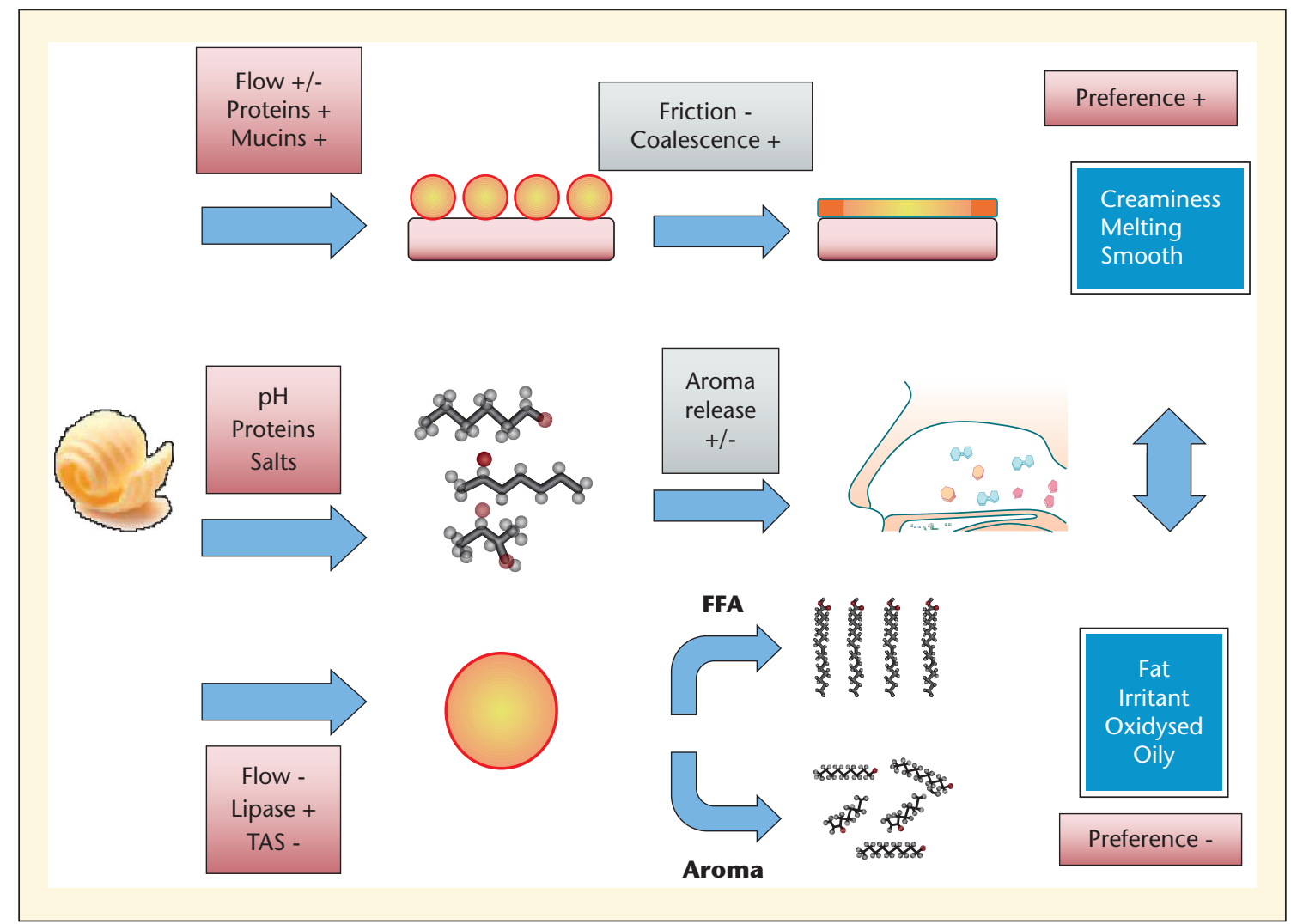

Figure 3. Proposed mechanisms for the role of saliva characteristics in the perception of and preferences for fat emulsifying products. These mechanisms are based on the different results published in the literature (Sarkar and Singh, 2012). Globally, preferences for fat are often described as linked to the texture of the fat present in the product. During oral processing, the salivary parameters that contribute the most to the destabilisation of the emulsion are salivary flow, the amount of proteins and the amount of mucins. Salivary flow participates in the clearance of the product from the surface of the tongue. High levels of proteins and mucins favour the flocculation and coalescence of the emulsion, principally by depletion phenomena and charge attraction. All these in-mouth processes favour the retention of the product on the tongue surface, enhancing the hedonic response to fat texture.

In contrast, other salivary compounds seem to contribute more to the rejection of the product. In emulsions with low hedonic values, low salivary flow leads to longer oral clearance and thus to enhancing the perception of undesirable characteristics of the product. High lipase activity should lead to the release of a higher amount of free fatty acids, which are considered to have a poor hedonic value because of their irritating and bitter notes (Stephan and Steinhart, 2000). Last, TAS must be considered with regard to the oxidation of emulsion perception and the oily characteristics of the product often linked to the presence of volatiles resulting from PUFA oxidation. For the aroma, saliva can modify the release of flavour from the product first in the oral cavity and then in the nasal cavity. This modification is due to not only the physicochemical properties of saliva ( $\mathrm{pH}$ and viscosity) but also the concentration and nature of small and large molecules present in the saliva. However, these phenomena depend mainly on the aroma compounds' characteristics and structure. Therefore, it is difficult to propose a general mechanism and thus identify a positive or negative influence of these phenomena on preferences. TAS: total antioxidant status, FFA: free fatty acids.

the proposal of a causal hypothesis based on the different results described in the literature. The main conclusions on the role of saliva are the following:

- Saliva plays a major role in the detection and perception of fat in the mouth by different mechanisms.

- Large interindividual variability is observed in saliva characteristics. This variability raises the question of its relationship with variability in fat sensory perception and the different modalities used to detect fat.
- Saliva can positively or negatively contribute to the preferences for fat.

- Other oral and salivary variables must be considered in the perception of fat, i. e., shear forces, melting, and the role of other proteins.

- The regulatory function of lipase needs to be clarified with research conducted on a larger number of subjects and/or targeted populations.

Currently, there are few papers on this subject, but there is growing interest in the field in the scientific community and industry. Answering the questions asked by the hypothesis formulated in this paper will permit the prioritisation of different variables involved in fat perception in the subject or the product and the proposal of more well-reasoned strategies for lowering and/or changing the fat in food products.

\section{Disclosure}

Conflict of interest: none. 


\section{REFERENCES}

Benjamins J, Vingerhoeds $M H$, Zoet FD, de Hoog EHA, van Aken GA. Partial coalescence as a tool to control sensory perception of emulsions. Food Hydrocoll 2009; 23: 102-15.

Chale-Rush A, Burgess JR, Mattes RD. Evidence for human orosensory (taste?) sensitivity to free Fatty acids. Chem Senses 2007; 32: 423-31.

Chale-Rush A, Burgess JR, Mattes RD. Multiple routes of chemosensitivity to free fatty acids in humans. Am / Physiol Gastrointest Liver Physiol 2007; 292: G1206-1212.

Degrace-Passilly P, Besnard P. CD36 and taste of fat. Curr Opin Clin Nutr Metab Care 2012; 15: 107-11.

Dresselhuis DM, de Hoog EHA, Cohen Stuart MA, Vingerhoeds $\mathrm{MH}$, van Aken $\mathrm{GA}$. The occurrence of in-mouth coalescence of emulsion droplets in relation to perception of fat. Food Hydrocoll 2008; 22: 1170-83.

Dresselhuis DM, Stuart MAC, van Aken GA, Schipper RG, de Hoog EHA. Fat retention at the tongue and the role of saliva: Adhesion and spreading of 'protein-poor' versus 'protein-rich' emulsions. J Coll Interface Sci 2008; 321: 21-9.

Feron G, Guichard E. Lipides et arômes : rôles dans la perception de la flaveur et du gras chez I'homme. Innovations Agronomiques 2010; 10: 69-80.

Gaviao MB, van der Bilt A. Salivary secretion and chewing: stimulatory effects from artificial and natural foods. I Appl Oral Sci 2004; 12: 159-63.

Genovese A, Piombino P, Gambuti A, Moio L. Simulation of retronasal aroma of white and red wine in a model mouth system. Food Chem 2009; 114: 100-7.

Grabenhorst F, Rolls ET, Parris BA, d'Souza AA. How the brain represents the reward value of fat in the mouth. Cereb Cortex 2011; 20: 1082-91.

Guichard E, Repoux M, Sémon E, Labouré H, Yven C, Feron G. Understanding the dynamics of flavor compounds release during food mastication of cheese products in function of oral physiology. In: T. Hofmann, W.
Meyerhof, P. Schieberle (Eds.). Advances and challenges in flavor chemistry \& biology. Proceedings of the 9th Wartburg Symposium. Freising (Germany): Deutsche Forschungsanstalt für Lebensmittelchemie, 2010.

Kawai T, Fushiki T. Importance of lipolysis in oral cavity for orosensory detection of fat. Am J Physiol Regul Integr Comp Physiol 2003; 285: 447-54.

Khan NA, Besnard P. Oro-sensory perception of dietary lipids: New insights into the fat taste transduction. BBA-Mol Cell Biol Lip 2009; 1791: 149-55.

Laugerette F, Gaillard D, Passilly-Degrace P, et al. CD36 involvement in orosensory detection of dietary lipids, spontaneous fat preference, and digestive secretions. I Clin Invest 2005; 115: 3177-84.

Mattes RD. Fat taste and lipid metabolism in humans. Physiol Behav 2005; 86: 691-7.

Mattes RD. Oral fat exposure alters postprandial lipid metabolism in humans. Physiol Behav 1996; 63: 911-7.

Mattes RD. Oral fat exposure increases the first phase triacylglycerol concentration due to release of stored lipid in humans. I Nutr 2002; 132: 3656-62.

Neyraud E, Palicki O, Schwartz C, Nicklaus S, Feron G. Variability of human saliva composition: Possible relationships with fat perception and liking. Arch Oral Biol 2012; 57: 55666.

Pepino MY, Love-Gregory L, Klein S, Abumrad NA. The fatty acid translocase gene CD36 and lingual lipase influence oral sensitivity to fat in obese subjects. / Lipid Res 2012; 53: 561-6.

Poette J, Lubbers S, Maison B, et al. The salivary reactor: an innovating tool for the categorization of food products through their aroma and taste compounds release profiles. In: T. Hofmann, W. Meyerhof, P. Schieberle, (Eds.). Advances and challenges in flavor chemistry \& biology. Proceedings of the 9th Wartburg Symposium. Freising (Germany): Deutsche Forschungsanstalt für Lebensmittelchemie, 2010.

Poette I, Mekoué I, Genot C, et al. Fat sensitivity in human: possible relationships with oral and saliva characteristics. 2012; Submitted.

Rolls ET. The neural representation of oral texture including fat texture. I Texture Stud 2011; 42: 137-56.

Rolls ET. The representation of the pleasantness of oral taste and texture in the brain. in: International Conference on Food Oral Processing - Physics, Physiology and Psychology of Eating. Leeds (UK), 1-5 July 2010.

Salles C, Chagnon MC, Feron G, et al. Inmouth mechanisms leading to flavor release and perception. Crit Rev Food Sci Nutr 2011; 51: 67-90.

Sarkar A, Singh H. 2012. Oral Behaviour of Food Emulsions. In: J. Chen and L. Engelen, (Eds.). Food Oral Processing: Fundamentals of Eating and Sensory Perception. Wiley-Blackwell, Oxford (United Kingdom), 2012.

Silletti $\mathrm{E}$, Vingerhoeds $\mathrm{MH}$, Norde $\mathrm{W}$, van Aken GA. The role of electrostatics in salivainduced emulsion flocculation. Food Hydrocoll 2007; 21: 596-606.

Stephan A, Steinhart H. Bitter taste of unsaturated free fatty acids in emulsions: contribution to the off-flavour of soybean lecithins. Eur Food Res Technol 2000; 212: 17 25.

Stewart JE, Feinle-Bisset C, Golding M, Delahunty C, Clifton PM, Keast RSJ. Oral sensitivity to fatty acids, food consumption and BMI in human subjects. Br / Nutr 2010; 104: 145-52.

van Aken GA, Vingerhoeds $\mathrm{MH}$, de Hoog EHA. Food colloids under oral conditions. Curr Op Coll Interface Sci 2007; 12: 251-62.

Vingerhoeds $\mathrm{MH}$, Blijdenstein TB], Zoet FD, van Aken GA. Emulsion flocculation induced by saliva and mucin. Food Hydrocoll 2005; 19: 915-22.

Vingerhoeds $\mathrm{MH}$, Silletti $\mathrm{E}$, de Groot J, Schipper RG, van Aken GA. Relating the effect of saliva-induced emulsion flocculation on rheological properties and retention on the tongue surface with sensory perception. Food Hydrocoll 2008; 23: 773-85.

Voho A, Chen J, Kumar M, Rao M, Wetmur J. Lipase expression and activity in saliva in a healthy population. Epidemiology 2006; 17: S336-S. 